\title{
INFLUENCIAS DEL EMBALSE DE YACYRETÁ SOBRE LOS ECOSISTEMAS COSTEROS
}

Fontana, José Luis ${ }^{(*)}$ y Iriart, David E. ${ }^{(*)}$

\section{Resumen}

La formación del embalse de la represa de Yacyretá (valle del río Paraná en las provincias de Corrientes y Misiones) determinó profundos cambios en los ecosistemas que ocupaban el valle de inundación. Con el llenado en 1994 desaparecieron unas 50.000 ha de bosques higrófilos y pajonales, más unas 300 islas con humedales, superficie que superó las 100.000 ha a cota $83 \mathrm{msnm}$. La elevación del embalse impactó sobre el régimen de agua del suelo, que se tradujo en cambios sucesionales y de sustitución en los ecosistemas costeros: fragmentos ahogados, nuevas superficies de pajonales higrófilos, invasión secundaria del bosque por elementos de la selva riparia y daños severos en especies mesófilas. La identificación de las etapas de sucesión en distintos momentos de la historia del embalse permite predecir posibles cambios bajo nuevas modificaciones del nivel de aguas y su aplicación a otros emprendimientos hidroeléctricos regionales. La predicción de estos cambios ayudará a la aplicación de acciones preventivas que impidan la pérdida de biodiversidad y de ecosistemas.
Palabras Clave: Embalse de Yacyretá, vegetación, modificaciones, sucesión vegetal.

\section{INTRODUCCIÓN}

La construcción de grandes embalses fue característico en la segunda mitad del s.XX. En Sudamérica, Brasil y Argentina llevaron adelante grandes emprendimientos (Itaipú, Yacyretá, Salto Grande, e.o.). Los embalses cubrieron extensas superficies, ahogando vegetación natural (Bosques) y seminatural (campos de pajonales), provocando grandes cambios en aquellos remanentes que quedaron en las costas. Desde el año 2000 el grupo de investigación en Ecología y Restauración realizamos estudios en el área de influencia de la represa de Yacyretá, parte de ellos en colaboración con investigadores de la UNaM. Resultados de estos estudios se plasmaron en numerosos informes técnicos, publicaciones y presentaciones en congresos (ver lista en Bibliografía).

El cierre de la represa de Yacyretá se produjo en 1994, año en el que el antiguo valle de inundación del río Paraná entre Ituzaingó (Corrientes) y Candelaria (Mi-

(*) Grupo de Investigación Ecología y Restauración - FACENA - UNNE

Laboratorio de Ecología Vegetal - Departamento de Biología / jlfontana@yahoo.com.ar 
siones) quedó totalmente inundado. La planificación establecía la elevación del nivel del embalse en etapas para alcanzar en 2011 la cota $83 \mathrm{msnm}$. Se formó un espejo de agua de más de $1500 \mathrm{~km} 2$.

La evaluación ecológica realizada en el lado argentino del embalse mostró la influencia de los cambios de nivel sobre la vegetación costera que quedó fuera del agua luego de las últimas elevaciones de la cota, y que derivó en profundos cambios sucesionales. Este tipo de estudios es pionero en Argentina, conociéndose algunos trabajos hechos en situaciones semejantes en Brasil (Pedralli, G. \& S.T. Meyer, 1996).

Los trabajos se realizaron en la margen argentina del Río Paraná, analizando los cambios ocurridos desde el cierre de la represa. Presentamos aquí a manera de ejemplo la situación de la vegetación en un sector del embalse, cerca de la desembocadura del Arroyo Itaembé, en el límite interprovincial Corrientes - Misiones, donde se observaron claramente los efectos. La aplicación del método de Evaluación Ecológica Rápida o Rapid Ecological Assessment permitió obtener la información necesaria para tomar decisiones relacionadas con la conservación en áreas críticas poco conocidas, con una alta biodiversidad o donde la biodiversidad se encuentra amenazada por acción humana (Sayre et al. 2000). Es un procedimiento que consiste en una serie de análisis detallados mediante el uso de información espacial generada con sensores remotos, que permiten delimitar áreas prioritarias para la conservación, detectar amenazas potenciales que ponen en peligro determinadas especies, dirigir investigaciones específicas, tales como inventario y moni- toreo y planificar acciones de restauración.

\section{MATERIALES Y MÉTODOS}

Para analizar las modificaciones, producto de la elevación de la cota, se estudiaron las unidades de vegetación de la costa argentina relacionadas con el área de inundación del embalse. Para ello se aplicó el método de Evaluación Ecológica Rápida (Sayre et al., 2000), con el objeto de adquirir, analizar y manejar información ecológica de una manera eficaz y en un lapso de tiempo breve. Se trabajó mediante la selección de transectas, describiéndose para cada una de ellas los ambientes, caracterizándolos por los tipos de vegetación, por relieve y la distancia al espejo de agua. Para el estudio de la vegetación se aplicó el método fitosociológico de Braun-Blanquet (Braun-Blanquet, 1979; Diershke, 1994; Matteucci \& Colma, 2000), adaptado a las transectas. La selección de los sitios de relevamiento se realizó en la franja correspondiente a la transecta, ubicada en sentido vertical al eje del embalse. Los censos fitosociológicos brindaron información florística de las comunidades, sobre la presencia de especies raras o pertenecientes a otras unidades de vegetación, y su abundancia El uso de imágenes satelitales permitió evaluar los cambios de las líneas de inundación y de las superficies de las distintas unidades de vegetación de los últimos doce años.

\section{RESULTADOS}

Río abajo de la desembocadura del Arroyo Itaembé, el relevamiento exhaustivo de la vegetación doce años después del llenado del embalse junto a los datos previos al cierre de la represa, resultaron esclarecedores acerca de las modificaciones producidas por el llenado del embalse y las 
posteriores elevaciones de cota. Las modificaciones de las condiciones de humedad del suelo determinaron cambios profundos en la distribución de las comunidades vegetales originales. Previo al llenado del embalse, esta zona correspondía a la antigua terraza no inundable del valle de inundación del río Paraná (figura 1 "A"). Una franja de bosque mesófilo acompañaba este límite de inundación, en algunos sectores cortado por pajonales que llegaban desde los campos aledaños. Ya en el valle de inundación, la Selva riparia y el Prebosque de "Ambay" y
"Sangre de drago" junto a pajonales higrófilos se repartían la superficie según humedad del suelo y frecuencia de inundaciones.

La construcción de la represa determinó: a) la inundación permanente del valle y con ello destrucción de la vegetación allí existente, b) cambios de las condiciones de humedad del suelo de la terraza del valle, hasta ese momento de carácter mesófilo, y c) procesos de sustitución y sucesión de la vegetación debido a los cambios ambientales.
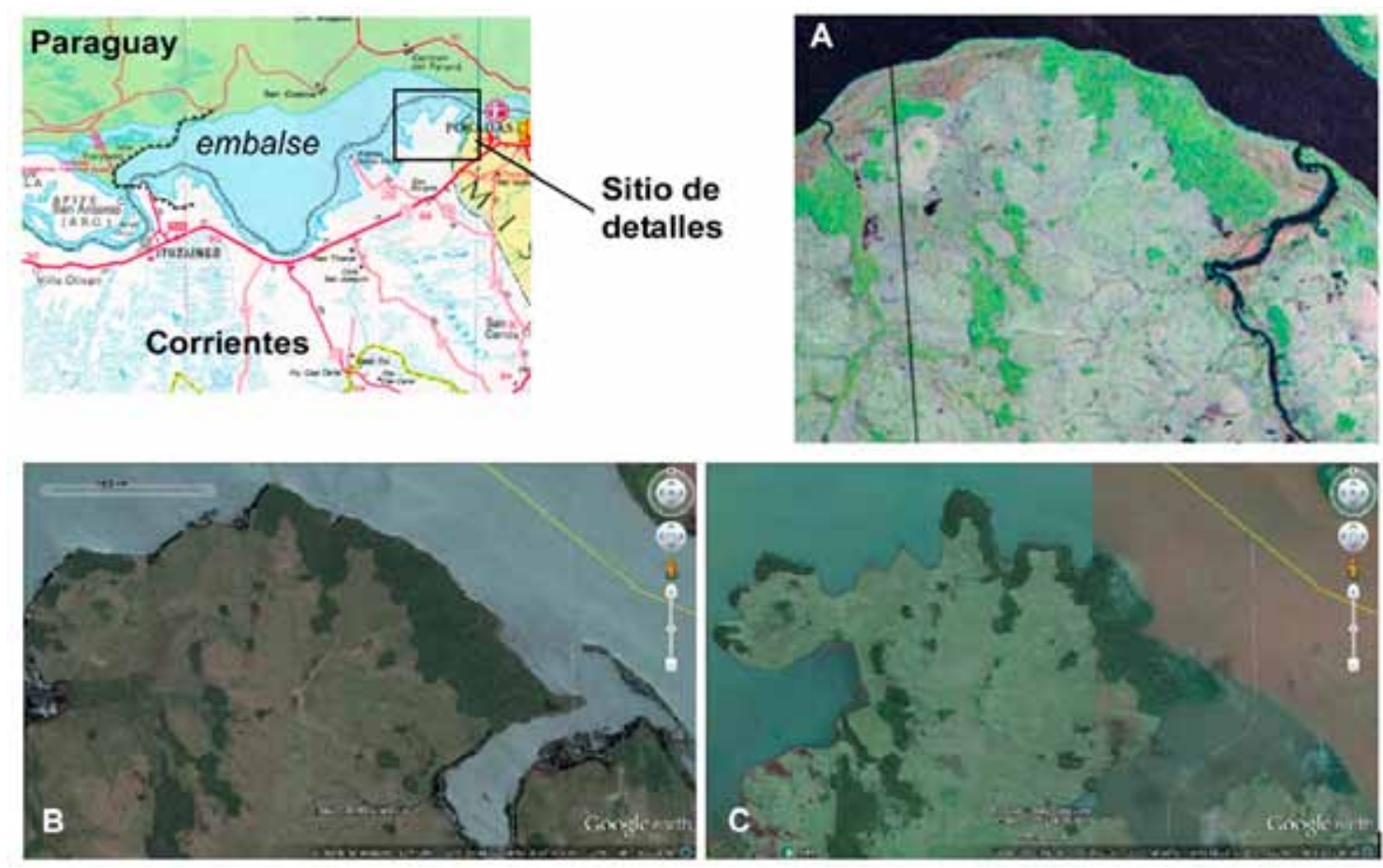

Figura 1. Cambios de los márgenes del embalse desde 1992 (previo al llenado) hasta la actualidad (2016) por efecto de sucesivas elevaciones de la cota. A: imagen de 1992; B: imagen de 2006 (cota 76 msnm); C: imagen de 2016 (cota 83 msnm).

Doce años después del cierre de la represa (2006), la vegetación mostraba claramente la tendencia sucesional, dando origen a tipos de vegetación en formas de franjas paralelas condicionado por el relieve que determinó un nuevo gradiente de humedad (tabla 1 y figura 2).
La figura 1 muestra claramente cómo cambió la línea de costa entre la situación previa al llenado (Figura 1, A), y la elevación a cota $76 \mathrm{msnm}$ (Figura $1, \mathrm{~B}$ ) y la definitiva a cota $83 \mathrm{msnm}$ (Figura 1, C). Se observa la disminución de la superficie ocupada por la vegetación y la ingresión 
de las aguas en las depresiones (bañados y esteros), y en los valles de los afluentes.

\section{Distribución de la vegetación costera}

Sobre el borde del embalse y a veces al-
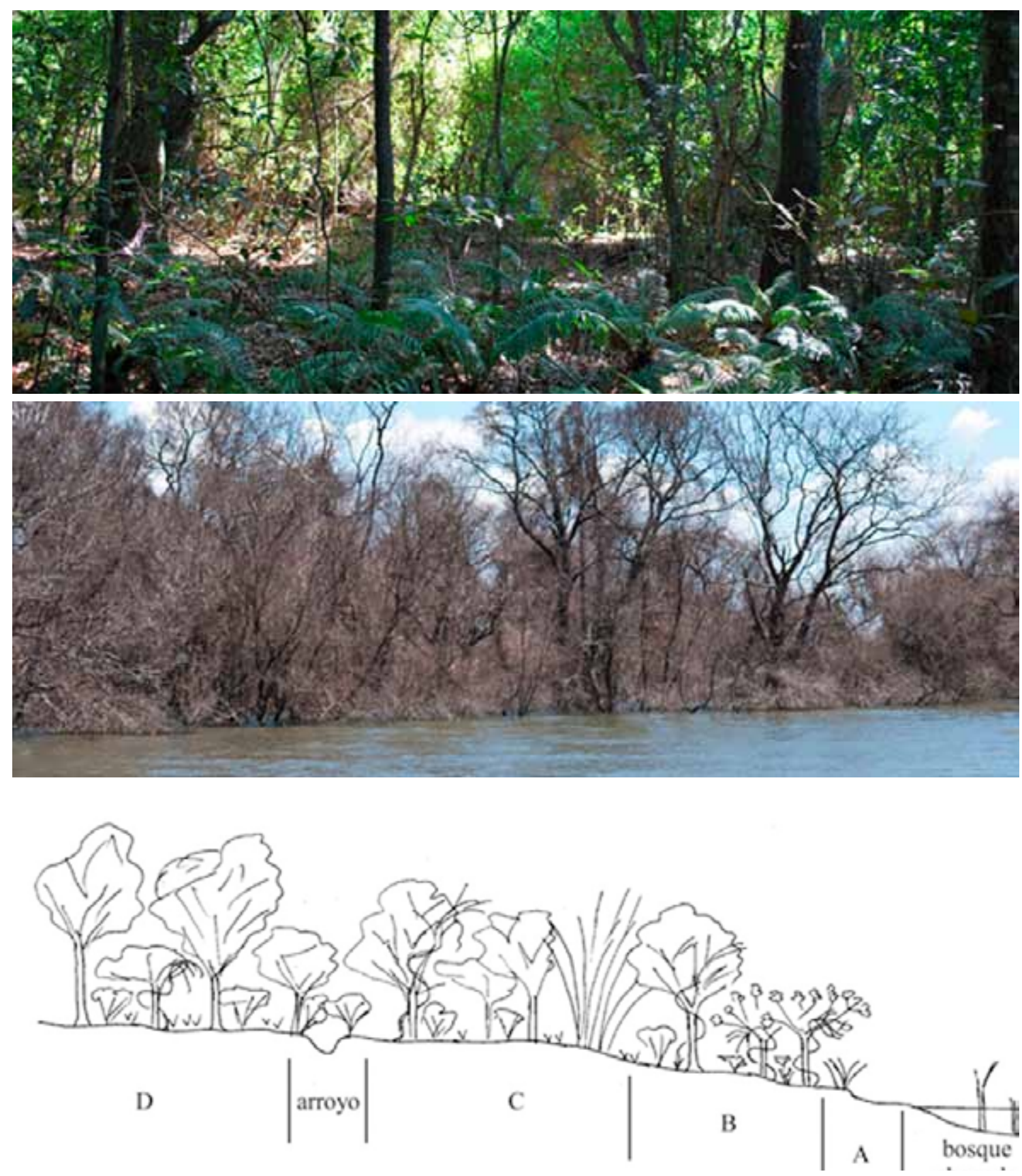

Fig. 2. Vegetación de la costa del embalse. Arriba, Vista del bosque de Arary a cota 76 msnm. B: vista del mismo bosque luego de alcanzarse la cota 83 msnm. Abajo: Perfil $N-S$ de la vegetación, rio abajo de la desembocadura del Ao.Itaembé (Solis et al., 2006). A: Pajonal de Panicum grumosum; B: Bosque mesófilo invadido por el Prebosque de "Ambay" y "Sangre de drago"; C: Bosque mesóflo invadido por elementos de la selva riparia; D: Bosque mesófilo conservado. 
canzado por el oleaje, se observaba un $\mathrm{Ca}^{-}$ ñaveral con Panicum grumosum (en la figura 2: "A"), con un ancho variable según el sitio, desde casi ausente hasta alcanzar más de 20 $\mathrm{m}$. Donde la erosión actuó fuertemente, el cañaveral desapareció y una playa con acumulación de arena precedía a una pequeña barranca de unos 30-40 cm de altura.

A este Cañaveral sigue una franja con restos del bosque mesófilo original invadido por elementos del Prebosque de "Ambay" (Cecropia pachystachya) y "Sangre de drago" (Croton urucurana) (en la figura 2: "B"). Quedan aún en pie algunos viejos y grandes ejemplares de Handroanthus heptaphyllus y Anadenanthera colubrina, con daños como consecuencia del cambio del régimen hídrico del suelo por efecto del embalse cercano. Esta franja, de unos 40-50 m de ancho, se inundó periódicamente con el ascenso del nivel de las aguas del embalse, durante las crecidas. El suelo permaneció húmedo casi todo el año, salvo sequías excepcionales; la humedad del suelo tiene aquí relación directa con el ascenso de la napa freática.

Más hacia el interior se encuentra un bosque mesófilo (en la figura 2: “C”) en mejor estado, invadido por elementos de la selva riparia como Inga verna ssp affinis (ejemplares jóvenes, de 6-7 $\mathrm{m}$ de altura), y la presencia de las llamativas matas casi infranqueables de la "tacuara brava" Guadua chacoensis. Ambos elementos son típicos de la costa de las islas. Los grandes ejemplares de Handroanthus heptaphyllus, Cordia americana y Parapiptadenia rigi$d a$ se observan en mejor estado, aunque muestran daños (alguna ramas muertas); las inundaciones son en esta parte menos duradera y sólo en situaciones excepcionales.

Finalmente en las zonas más elevadas, no alcanzadas por inundaciones, crece en todo esplendor el Bosque mesófilo conservado (en la figura 2: "D"). Aparentemente la explotación se detuvo hace ya mucho tiempo; algunos tocones grandes descompuestos son testigos. Grandes ejemplares con hasta $1,90 \mathrm{~m}$ de DAP aparecen dispersos formando parte de un estrato de árboles altos sobresaliente que alcanza 25-30 m de altura. Esta zona corresponde a la parte más elevada de la terraza antigua, lo que evitó que este Bosque sea alcanzado en la última elevación de la cota.

\section{La situación actual}

La última elevación y ¿definitiva? Del embalse a cota $83 \mathrm{msnm}$ frenó todos los procesos sucesionales descriptos, ya que la inundación permanente sólo dejó afuera del agua el Bosque mesófilo conservado en la parte más alta de la terraza. El resto de las unidades que habían sido estudiadas quedaron sumergidos; en algunos sitios se había procedido a la remoción previa de biomasa, mientras que en otros aún se observan los árboles muertos en pie en medio del agua.

En otros sitios cercanos como en Rincón Ombú, la inundación alcanzó remanentes del Bosque de "Arary" que crecía en forma de una mancha costera, en el que se encontraban grandes ejemplares de este árbol, junto a la población más grande helechos arborescentes (Cyathea atrovirens) registradas para la provincia de Corrientes. Tareas previas realizada por este equipo de trabajo lograron el rescate de algunos ejemplares de ambas especies.

Cabe aclarar que a cota $76 \mathrm{msnm}$ se perdieron en forma definitiva unas 52.600 ha de ecosistemas terrestres, alcanzando a 107.600 ha la pérdida a cota 83 (Blanco et al., 2003). 
Estos datos incluyen unas 50.000 ha correspondientes a unas 300 islas con humedales.

La antigua y larga influencia humana en toda el área estudiada, determinó una lenta fragmentación del paisaje original, la reducción del bosque mesófilo, formación de isletas de bosque, discontinuidad del corredor natural boscoso, aumento de la superficie de los pajonales y pastizales, eliminación de áreas de pastizal por cultivos y formación de "islas" de pastizal por forestación.

La elevación de la cota del embalse produjo una influencia enorme en pocas semanas, con profundas modificaciones en ecosistemas y rápidos cambios en la dinámica hídrica del suelo, equivalente a décadas de influencia humana tradicional.
Ante esta situación se establecieron criterios y prioridades para la conservación de la diversidad vegetal para minimizar la afectación de los ecosistemas mencionados. Se realizaron las primeras acciones de trabajos de restauración de bosques en Santa María con el objeto de proteger especies amenazadas como el helecho arborescente Cyathea atrovirens y el "arary" Calophyllum brasiliense, una especie recientemente citada para la flora argentina (Rodríguez et al., 2009).

Promover la conservación seleccionando nuevas áreas o ampliando las ya existentes, trabajando en su recuperación total o parcial y el uso sostenido es aún una etapa pendiente. Esta acción demandará nuevos monitoreos para el seguimiento de los cambios a largo plazo.

\begin{tabular}{|c|c|c|c|c|}
\hline $\begin{array}{l}\text { Unidad de } \\
\text { vegetación }\end{array}$ & $\begin{array}{c}\text { Altura } \\
\text { (msnm) }\end{array}$ & Fisonomia & Principales especies & $\begin{array}{l}\text { Especies } \\
\text { indicadoras de } \\
\text { cambios }\end{array}$ \\
\hline $\begin{array}{l}\text { Cañaveral } \\
\text { de Panicum } \\
\text { grumosum }\end{array}$ & 74 & $\begin{array}{l}\text { Cañaveral denso en el borde del } \\
\text { agua. Un estrato alto }(2 \mathrm{~m}) \text { y uno } \\
\text { intermedio }(0,70 \mathrm{~m}) \text {. Cobertura: } \\
90 \% \text {. Suelo arenoso, con mucha } \\
\text { materia orgánica, muy oscuro. }\end{array}$ & $\begin{array}{l}\text { Panicum grumosum, Cuphea } \\
\text { melvilla, Paspalum sp., } \\
\text { Polygonum hispidum, }\end{array}$ & $\begin{array}{l}\text { Inga vema ssp } \\
\text { affinis }\end{array}$ \\
\hline $\begin{array}{l}\text { Prebosque } \\
\text { con restos } \\
\text { del bosque } \\
\text { mesófilo }\end{array}$ & $85-87$ & $\begin{array}{l}\text { Bosque mesófilo invadido } \\
\text { secundariamente por el } \\
\text { Prebosque. Presencia de } \\
\text { muchos árboles caidos, dañados } \\
\text { y unos pocos en buen estado } \\
\text { indican daños por cambios en el } \\
\text { régimen de agua del suelo. } \\
\text { Relieve con leve inclinación } \\
\text { hacia el embalse. Cuatro } \\
\text { estratos, además de trepadoras } \\
\text { y epifitos. Cobertura: } 95 \% \text {. } \\
\text { Suelo areno limoso, oscuro y } \\
\text { muy húmedo. Con hojarasca } \\
\text { acumulada. }\end{array}$ & $\begin{array}{l}\text { Ocotea suaveolens, Guadtua } \\
\text { chacoensis, Cecropia } \\
\text { pachystachya, Inga vema ssp } \\
\text { affinis, Guarea spiciflora, } \\
\text { Psidium kennedianum, Luehea } \\
\text { divaricata, Inga semialata. } \\
\text { Trepadoras: } \\
\text { Aristolochia macroura, Urera } \\
\text { aurantiaca, Hippocratea } \\
\text { volubilis, Cayaponia podantha, } \\
\text { Chusquea ramosissima }\end{array}$ & $\begin{array}{l}\text { Del bosque original: } \\
\text { Handroanthus } \\
\text { heptaphyllus, } \\
\text { Anadenanthera } \\
\text { cebil, } \\
\text { Pterogyne nitens, } \\
\text { Peltophorum } \\
\text { dubium, Pouteria } \\
\text { gardneriana, } \\
\text { Trichilia elegans, } \\
\text { Rollinia } \\
\text { emarginata, } \\
\text { Doryopteris } \\
\text { concolor. }\end{array}$ \\
\hline $\begin{array}{l}\text { E1 Bosque } \\
\text { mesófilo con } \\
\text { "lapacho"y } \\
\text { "curupay" }\end{array}$ & 89 & $\begin{array}{l}\text { Se encuentra a continuaciónde la } \\
\text { franja invadida secundariamente } \\
\text { por el prebosque con Cecropia } \\
\text { pachystachya, en una zona con } \\
\text { leve pendiente hacia el embalse. } \\
\text { Cuatro estratos, además de } \\
\text { trepadoras y epifitos; árboles } \\
\text { altos, hasta } 28 \text { m de altura. } \\
\text { Trepadoras y epifitos escasos. } \\
\text { Suelo areno limoso, oscuro, } \\
\text { húmedo, con acumulación pobre } \\
\text { de hojarasca. }\end{array}$ & $\begin{array}{l}\text { Handroanthus heptaphylla, } \\
\text { Ocotea suaveolens, } \\
\text { Anadenanthera cebil, Guadua } \\
\text { chacoensis, Lonchocarpus } \\
\text { muehbergiamus, Jacaratia } \\
\text { dodecaphylla, Campomanesia } \\
\text { xanthocarpa, Bastardiopsis } \\
\text { densiflora, Guazuma ulmifolia, } \\
\text { Terminalia triflora, Ruprechtia } \\
\text { laxiflora, Albizia hassleri, } \\
\text { Parapiptadenia rigida, Pouteria } \\
\text { gardneriana. }\end{array}$ & $\begin{array}{l}\text { Aparecen aquí } \\
\text { especies de } \\
\text { tendencia higrófila } \\
\text { mostrando los } \\
\text { cambios de } \\
\text { humedad del suelo: } \\
\text { Inga vema ssp } \\
\text { affinis, Cecropia } \\
\text { pachystachya. }\end{array}$ \\
\hline
\end{tabular}

Tabla 1. Características de las unidades de vegetación desde la costa del embalse hacia las lomadas. 


\section{CONCLUSIONES}

Los estudios y el seguimiento realizado permitieron arribar a las siguientes conclusiones:

- El bosque observado río abajo de la desembocadura del Itaembé es una mezcla del viejo Bosque mesófilo con "lapacho" y "curupay", y el Prebosque de "ambay" y "sangre de drago".

Bosque de lapacho y curupay

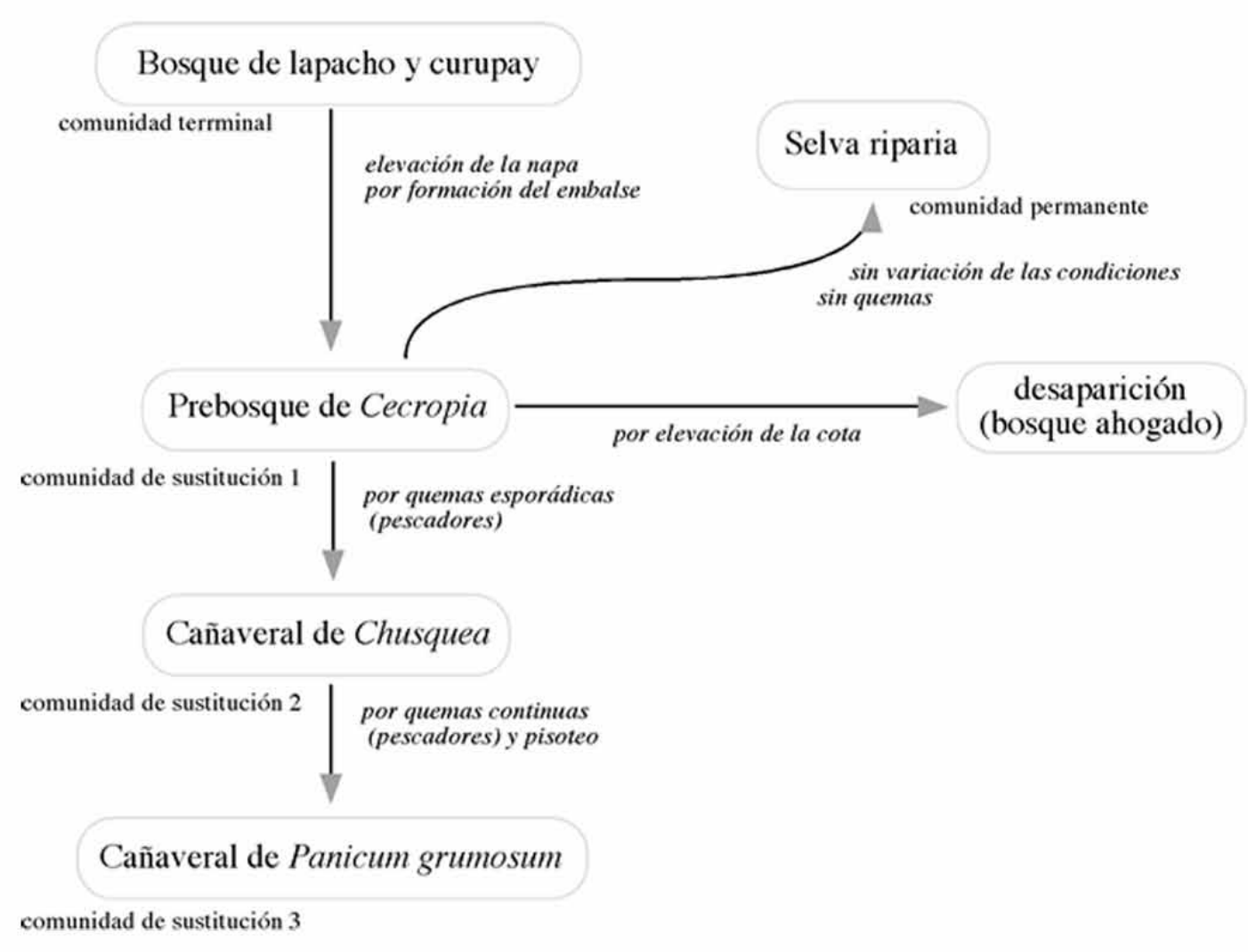

- La presencia de árboles caídos por efecto combinado de tormentas y falta de sustentación (raíces debilitadas), de árboles en pie dañados o enfermos son testigos de las modificaciones ambientales producidas por el ascenso de la napa freática.

- La modificación del régimen de agua del suelo por elevación de la napa y la desaparición de la influencia del hombre (fuego, tala, pastoreo, etc.) determinarán a largo plazo el desarrollo de la Selva riparia como

Fig. 3. Relaciones de sustitución y sucesión en la vegetación en la costa argentina del embalse Yacyretá, zona de la desembocadura del Arroyo Itaembé (Solís et al., 2006).

- Es un resultado del cambio de régimen de agua en el suelo por efecto de la formación del embalse. Este cambio en los gradientes de humedad, determinaron un lento reemplazo de la vegetación mesófila (comunidad terminal) por otra de carácter más higrófilo (comunidad de sustitución 1 ). comunidad vegetal permanente, es decir sin evolución posterior mientras las condiciones no cambien nuevamente (figura 3 ).

- En los sitios visitados con frecuencia por pescadores (quema periódica) se establece el Cañaveral de Panicum 
grumosum. Si las quemas son esporádicas y muy espaciadas, inducirán al establecimiento de un Cañaveral de Chusquea. Estas comunidades se desarrollan en un muy corto plazo ya que sus integrantes son plantas de rápido crecimiento.

- La última elevación de la cota implicó la desaparición de la franja costera que estuvo en transformación hacia la Selva riparia y la desaparición de gran parte de la superficie del Bosque mesófilo por su transformación hacia una vegetación de carácter higrófilo (figura 1).

La figura 3 muestra los procesos de cambio debidos a las modificaciones ambientales productos de la formación del embalse de Yacyretá. Los estudios permitieron establecer este esquema de sucesión que es aplicable a otros emprendimientos hidroeléctricos futuros proyectados en los ríos Paraná y Uruguay. Ayudará a pre-

\section{BIBLIOGRAFÍA}

Blanco D.E.,A.F.Parera \& M.H.Acerbi (Coordinación). 2003. La Inundación Silenciosa. El aumento de las aguas en los esteros del Iberá: la nueva amenaza de la Represa Yacyretá. Versión ampliada y actualizada. Fundación Vida Silvestre Argentina. 56 páginas. Buenos Aires.

Braun-Blanquet, J. (1979). Fitosociología. Bases para el estudio de las comunidades vegetales. H.Blume Edic. Madrid. 820 p.

Fontana, J.L. (2008). Vegetación y diversidad de ambientes en la Reserva $\mathrm{Na}$ tural Isla Apipé Grande, Provincia de Corrientes, Argentina. Miscelánea INSUGEO 17 (2): 407-424. Tucumán. decir los cambios posibles y así tomar las decisiones previas que eviten profundas modificaciones que conduzcan a la pérdida de biodiversidad y de ecosistemas.

\section{Agradecimientos}

El trabajo formó parte de los proyectos de investigación F013-2008, F0042010 y F007-2014 acreditados por la Secretaría Gral. de Ciencia y Técnica de la UNNE. Un convenio de trabajo con la Entidad Binacional Yacyretá facilitó el acceso a los lugares de trabajo.

Integrantes de Grupo de Investigación Ecología y Restauración: Dr. J.L.Fontana (Director), Dr. David E. Iriart (Co-Director), Lic. Silvia C. Zaninovich (Becaria CONICET), Lic. María del R. Montiel (Becaria CONICET), Lic. Daniela Artzen (Adscripta).

Fontana, J.L. (2015). Flora y Vegetación del Nordeste de Corrientes y sur de Misiones. En: El Patrimonio Natural y Cultural en el área de influencia del Embalse de Yacyretá, Argentina. Cap. 1, P. 9-27. Fundac. Felix de Azara. Buenos Aires. ISBN 978-987-3781-21-6.

Fontana, J.L., M. E. Rodríguez, A. E. Cardozo y D. Iriart (2007). Confirmación de la presencia de Cyathea atrovirens (Cyatheaceae) en la Provincia de Corrientes, Argentina. Bol. Soc. Argent. Bot . 42 (3-4): 325-327. ISSN 0373-580X.

Fontana, J.L. (2015). ¿̨Por qué restaurar ecosistemas? La experiencia con los bosques ribereños del embalse Yacyretá , provincia de Corrientes. Extensionismo, Innovación y Transferencia 
Tecnológica-Claves paraeldesarrollo-Vol.2: 148-156. Fac. de Cs. Exactas y Nat. y Agrim., UNNE. Corrientes. ISSN 2422-6424.

Iriart, D., J. L. Fontana, M. Rodríguez \& A. Cardozo (2012). La presencia de de Mucuna sloanei (Fabaceae) en la provincia de Corrientes, Argentina. Kurtziana 35(2): 15-18. Córdoba. ISSN 0075-7314.

Pasián, C., Y. E. Di Blanco, J. L. Fontana \& N. Fariña (2015). Composición de Mamíferos medianos y grandes de la reserva Natural Provincial Rincón de Santa Maria (Corrientes, Argentina): Comparación con su zona de amortiguamiento y estado de conservación. Mastozoología Neotropical 22(1): 187-194. ISSN 0327-9383. Mendoza.

Matteucci, S.D. \& A.Colma (2002). Metodología para el estudio de la vegetación. Secretaría Gral de la OEA.Serie Biología no 22 (1ª .edic. 1982, edic. digital 2002). Washington DC.

Pedralli, G. \& S.T. Meyer (1996). Levantamento da vegetaçâao aquática ("macrofitas") e das florestas de galeria na área da Usina Hidrelétrica de Nova Ponte, Minas
Gerais. BIOS, Cadernos do Depto. de Cs.Biológicas da PUC-Minas, 4(4): 49-60.

Rodriguez, M. , A. E. Cardozo, J.L.Fontana \& D. Iriart. (2009). Estudio de las comunidades vegetales ribereñas del área inundable del embalse mediante la metodología de evaluación ecológica rápida (EER). p.74-77. En: Gavazzo, G. VI Jornadas Científico Tecnológicas. Fac. Cs. Ex., Químicas y Nat., Univ. Nac. Misiones. 1a. edic. Posadas. Edit. Univ. UNaM. ISBN 978-950-579-091-3. 440 p.

Rodríguez, M., A.E.Cardozo, E.R.Krauczuk, J.L.Fontana \& D.E.Iriart (2009). Calophyllum brasiliensis (Clusiaceae). Nuevo registro para la flora del Nordeste de la Argentina. Bol. Soc. Arg. Bot. 44 (3-4): 361-366. ISSN 0373-580X.

Solis, G., E. Krauzuck, J. L. Fontana, M. Rodríguez \& A. Cardozo. 2006. Evaluación ecológica rápida de las áreas de embalse inundables a cota 83. Informe inédito. Entidad Binacional Yacyretá. 120 p. Ituzaingó. 